\title{
STUDI EMPIRIS LEAN MANUFACTURING DALAM MAMBANGUN DAYA SAING USAHA
}

\author{
Sumartono ${ }^{1}$, Petrus Megu' \\ ${ }^{1}$ Fakultas Ekonomi dan Bisnis Universitas Merdeka Malang
}

\begin{abstract}
:
The purpose of this research is to analyze the effect of lean manufacturing to the business competitiveness. The research population is all craftsmen shoes and sandals in Toyomerto, Malang. By simple random sampling technique, the researcher uses 105 repondents. Primary data were analyzed by structural equation modeling (SEM). Based on the analysis, it was revealed that lean manufacturing plays a significant role to the business competitiveness. It means that, in order to build the business competitiveness of craftsmen shoes and sandals in Toyomerto, Malang Regency, they should begin to applicate the concept of lean manufacturing. That concept can make these small business entities more competitive and sustainable.
\end{abstract}

Keywords: Lean Manufacturing, Business Competitiveness

\section{PENDAHULUAN}

Era globalisasi telah memunculkan banyak ketidakpastian perekonomian akhirakhir ini. Namun demikian, industri kecil termasuk para pengrajin bisa jadi dapat menemukan momentum terbaiknya. Hal itu karena produknya yang dibuat dengan konsep handmade, tentu memiliki keunikan tersendiri. Apalagi dengan berbagai inovasi tampilan yang berujung pada makin meningkatnya kualitas dan varian produk yang dihasilkan. Menurut Schumpeter (1883-1950), berpendapat bahwa pada saat berlangsungnya era perubahan ini merupakan momentum terbaik melakukan inovasi. Ketika semuanya serba sulit, maka dituntut semangat untuk memecahkan kebuntuan tatanan sistem melalui cara-cara inovatif dan kreatif. Tapi tentunya, diperlukan sentuhan semangat kewirausahaan, termasuk sentuhan teknologi modern untuk melakukan inovasi dan kreatifitas tersebut.

Terungkap dalam temuan riset dari The National Institute of Standards and Technology - Manufacturing Extension Partnership pada tahun 2013 terungkap bahwa implementasi model lean manufacturing yang efektif memberikan banyak benefit signifikan diataranya dalam format : 1) mengurangi work in process sampai dengan $90 \%, 2$ ) menekan lead time sampai dengan 95\%, 3) meningkatkan produktifitas antara $10-40 \%$, 4) meningkatkan kualitas $25-75 \%, 5)$ meningkatkan kerjasama tim dan komunikasi, 6) benefit lain yang dapat meningkatkan aliran produk.

Berdasarkan hasil survey awal ternyata pengrajin sandal dan sepatu yang terdapat masih eksis di sentra pengarjin Toyomerto, Singosari Kabupaten Malang ternyata relatif banyak jumlahnya. Berdasarkan informasi yang didapat dari ketua paguyuban pengrajin industri kecil tersebut, jumlahnya mencapai 142 pengrajin. Yang menarik, rata-rata jumlah pekerja pada setiap usaha kecil tersebut berjumlah 4-5 orang, diantaranya termasuk pemilik usaha. Tentu dari aspek penyerapan tenaga kerja bisa dianggap cukup baik, ditengah sulitnya mendapatkan kesempatan untuk bekerja.

Sayangnya, banyak pengrajin tersebut dihadapkan pada setumpuk persoalan. Perkembangannya terus melambat sebagai 
implikasi kurangnya mendapatkan sentuhan pembinaan manajemen sehingga pengelolaannya jauh dari efisien dan ragam produknya yang tidak banyak berubah dengan cepat. Persoalannya makin rumit karena makin maraknya bisnis serupa yang berskala besar dengan varian produk makin banyak dan juga cukup menarik. Tentu realitas ini menjadi ancaman serius yang dapat mengganggu kelangsungannya, termasuk pula kontribusinya pada perekonomian daerah, baik pada aspek ketenagakerjaan sampai pada kemungkinan meningkatnya angka pengangguran sebagai akibat dari kebaradaan usaha tersebut yang berpotensi mengalami kebangkrutan.

Oleh karena itu, pengembangan sektor ini menjadi sebuah tumpuan baru. Lebih-lebih Kabupaten Malang sebagai tujuan wisata akhir pekan, sehingga tentunya merupakan pasar potensial bagi para pengrajin tersebut. Apalagi, pada awal tahun 2016 telah memasuki era Mayarakat Ekonomi ASEAN, yang tentu berimplikasi pada makin luasnya pangsa pasar produk para pengrajin tersebut. Namun harus diingat, meningkatnya peluang pasar tersebut pasti akan diikuti meningkatnya iklim kompetisi di pasar. Maka, upaya yang harus dilakukan adalah membangun daya saing melalui implementasi model lean manufacturing pada sentra pengrajin sepatu dan sandal Toyomerto, Singosari, Kabupaten Malang, yang memang secara teoritik kemudian dapat mendorong tumbuh dan berkembangnya industri kecil tersebut menjadi lebih berdaya saing.

Sebagaimana diketahui, daya saing adalah jantung kinerja entitas bisnis. Daya saing pada dasarnya tumbuh dari nilai atau manfaat yang diciptakan bagi para pembelinya yang lebih dari biaya yang harus dikeluarkan untuk menciptakannya. Nilai atau manfaat inilah yang sedia dibayar oleh pembeli, dan nilai yang unggul berasal dari penawaran harga yang lebih rendah ketimbang harga pesaing untuk manfaat setara atau penawaran manfaat unik yang melebihi harga yang ditawarkan (Porter, 1994). Daya saing juga sebagai strategi benefit dari perusahaan yang melakukan kerjasama untuk berkompetisi lebih efektif dalam market place. Day dan Wensley (2008) menyatakan ada dua pijakan dalam mencapai keungulan bersaing yaitu keunggulan sumber daya dan keunggulan posisi.

Colgate (2009) menjelaskan daya saing sebagai posisi organisasi unik terhadap pesaingnya. Daya saing dapat diperoleh sebagian besar dari sumberdaya dan modal. Sumberdaya yang dimaksud adalah kekuatan dan kelemahan kinerja pemasaran, sedangkan modal diartikan sebagai kemampuan perusahaan dalam mengelola sumberdaya yang dimiliki untuk bekerja sama seperti tim kerja dalam satu departemen. Dengan kata lain tinggi rendahnya kinerja pemasaran akan berpengaruh kepada tinggi rendahnya daya saing perusahaan. Daya saing bisa diciptakan dengan pengetahuan yang benar akan variabelvariabel yang mempengaruhinya dan contoh kongkritnya dengan model lean manufacturing (Landgehemm, 2011).

Model tersebut akan menghilangkan non value added process, sebagai merupakan serangkaian kegiatan atau proses bisnis yang tidak memberikan nilai tambah, baik pada kualitas maupun kuantitas produksi (Huihui, 2014). Beberapa hal yang masuk dalam kategori kegiatan atau proses bisnis yang tidak memberikan nilai tambah tersebut diantaranya: a) Overproduction, hal ini mungkin sebagai kondisi yang benar-benar berbiaya besar. Sebuah tindakan yang hanya membuat produk yang lebih awal dan lebih cepat daripada proses selanjutnya yang membutuhkan. Dalam semua kasus, kelebihan menyebabkan persediaan yang tidak dibutuhkan. Kondisi ini sebuah pemborosan, karena tidak menambah nilai ; b) Inventory, dalam konsep ini inventory dianggap limbah. ini pasokan apapun lebih dari sebuah onepiece flow melalui proses, termasuk dalam 
proses dan barang jadi. Memegang persediaan biaya uang - sekitar 25 persen dari nilai persediaan jika dipegang selama satu tahun; c) Defect, tindakan yang buang-buang waktu yang meliputi bahan, tenaga kerja, jam mesin, memeriksa, menyortir atau ulang. Penyebabnya dapat pelatihan yang tidak memadai, kontrol proses yang lemah, pemeliharaan kekurangan dan/ spesifikasi teknik lengkap. Hal ini dapat mencakup inspeksi tambahan atau tidak benar, salinan tambahan dari dokumen dan lebih atau pemrosesan berlebihan "just-in-cases." Percepatan proses karena gagal memenuhi jadwal juga adalah pemborosan; d) Transportation, kegiatan memindah bahan dalam proses manufaktur dapat menambahkan biaya, tapi tidak ada nilai. Tidak hanya tindakan mengangkut menambah biaya, juga biasanya melibatkan menggunakan peralatan mahal. Biaya lainnya adalah ruang, menegangkan dan orang-orang dan sistem yang dibutuhkan untuk melacak materi; e) Waiting, ini termasuk semua waktu idle, seperti menunggu bagian dari operasi upstream dan menunggu perkakas, set-up dan instruksi. Menunggu pekerja secara umum menjadi perhatian yang lebih besar dari mesin digunakan; f) Motion, setiap orang dan / atau kegiatan mesin yang tidak menambah nilai produk dianggap limbah. Gejalanya termasuk waktu mencari alat, penanganan produk tambahan, berjalan dan pengaturan produk, susun, dll Penyebab mencakup tata letak yang buruk dan desain pabrik tempat kerja, pelatihan yang tidak memadai, pengolahan lemah dan perubahan jadwal konstan untuk mengurangi masalah pengiriman tepat dan waktu; g) Underutilizing Worker, faktor-faktor seperti budaya perusahaan, praktik mempekerjakan karyawan, gaya manajemen, tingkat turnover dan moral, semua berkontribusi terhadap tidak menggunakan potensi kemampuan tenaga kerja dengan sepenuhnya.
Selanjutnya, lean manufacturing adalah sebuah pendekatan baru dalam meminimalkan kegiatan yang sia-sia. Perlu diketahui bahwa dinamika perilaku pelanggan telah menggeser banyak perusahaan manufaktur dari produksi massal produk standar kecil-banyak produksi produk disesuaikan, dengan fokus yang lebih besar pada kualitas. Banyak perusahaan terus menghasilkan banyak besar berdasarkan perkiraan, dengan batch didorong dari departemen ke departemen dan dengan orangorang terlatih dalam terbatas, tugas yang berulang. Tapi itu menjadi jelas bahwa pendekatan ini menyebabkan persediaan yang berlebihan, terlalu banyak gerakan dan menunggu dan sumber daya terbuang pada orang, pabrik dan peralatan, semuanya pada peningkatan biaya.

Lean manufacturing adalah suatu pendekatan sistematis untuk mengidentifikasi dan mengeliminasi semua aktivitas tidak bernilai tambah melalui perbaikan terusmenerus untuk memungkinkan aliran produk berjalan lancar dalam mengejar kesempurnaan (Rolland etall, 2013).

Fokusnya menghilangkan kegiatan nonnilai tambah sekaligus menyederhanakan aktivitas nilai tambah. Pendekatan yang berorientasi pada orang dengan memberdayakan tim untuk mengambil tindakan menuju perbaikan adalah cara terbaik dan efektif menggunakan sumber daya yang paling berharga perusahaan dan juga stakeholder-nya. Setiap aktivitas yang tidak menambah ukuran pasar atau fungsi dari produk adalah non-nilai tambah kegiatan, atau limbah yang bersandar berusaha untuk menghilangkan. Menariknya, banyak produsen bahkan tidak mengenali beberapa ini sebagai limbah, tetapi kejahatan hanya perlu melakukan bisnis. Dengan demikian, lean manufacturing dapat dimaknai sebagai sebuah model bisnis yang berupaya memenuhi harapan pelanggan dengan menyediakan produk berkualitas dengan harga tejangkau. Lean manufacturing fokus pada 8 (delapan) 
pemborosan yang meliputi overproduction, inventory, defects, processing, transportation, waiting, dan motion serta extra people.

Pendekatan terbaik untuk memulai menerapkan model lean manufacturing adalah melakukan self-assessment. Observasi ke pusat kerja, area teknik, pengendalian produksi dan bagian pesanan dan memilih kelompok lini produk tertentu. Amati kekerapan set-up, panjang set-up, kemajuan bekerja yang signifikan, pusat-pusat kerja kritis, kemacetan arus, keterbatasan kapasitas, pelanggan utama, persediaan besar dan produk yang kompetitif.

Kemudian, carilah produk yang melewati proses pengolahan yang sama dan peralatan produksi umum pada akhir proses produksi. Selanjutnya, memilih kelompok lini produk berdasarkan langkah-langkah fabrikasi hulu yang melayani banyak lini produk dalam batch mode tidak akan memberikan nilai tambah. Setelah memilih lini produk tertentu, tempatkan diri anda pada posisi pelanggan, melacak desain, konsistensi dan seterusnya. Selanjutnya, tahapan penerapan model lean manufacturing adalah : a) Mengidentifikasi nilai produk (barang/jasa) berdasarkan perspektif pelanggan, b) Mengidentifikasi value stream process maping (pemetaan proses pada value stream) untuk setiap produk, c) Menghilangkan semua pemborosan yang tidak bernilai tampah pada semua aktivitas sepanjang value stream, d) Meorganisasikan agar material, infomasi dan produk mengalir secara lancar dan efisien sepanjang value stream, e) Mengejar kesempurnaan. Dengan terus menerus mencari berbagai teknik dan alat untuk mencapai kesempurnaan tanpa pemborosan (Rolland et.all, 2013).

Sebuah artikel dengan judul "The Role \& Importance of Lean Manufacturing in Manufacturing Industry" mengungkapkan bahwa lean manufacturing mempunyai peran sangat penting pada industri manufaktur. Hal itu karena model tersebut bukan hanya dapat mengidentifikasi pemborosan melainkan juga dapat mengeliminasinya (Gupta et all, 2014).

Kemudian, pentingnya implementasi model lean manufacturing terungkap pada beberapa artikel hasil penelitian diantaranya yang berjudul "Implementation of Lean Manufacturing Principles in Foundries" menyatakan bahwa lean manufacturing dapat meminimalkan non value added process dalam wujud mereduksi pemborosan yang kemudian dapat meningkatkan kualitas (Tameakar, Tirawi dan tandon, 2014). Pendapat tersebut makin diperkuat pada artikel hasil penelitian alin yang berjudul "Value Stream Mapping : A Lean Tool "yang mengungkapkan bahwa lean manufacturing juga dapat menekan inefisiensi dalam proses produksi. Bahkan ditambahkan dalam pendapatnya bahwa implementasi model tersebut akhirnya dapat meningkatkan kualitas proses produksi secara keseluruhan (Putran, et all, 2014). Temuan-temuan riset empiris tersebut juga makin diyakini karena didukung oleh sebuah artikel yang berjudul "Managing Waste Elimination database in lean manufacturing: Improve Problem Solving Capability" yang menyatakan bahwa lean manufacturing sebagai model paling efektif dalam mengelola dan mengeliminir segala bentuk pemborosan proses produksi (Nurazlin dan Huihui, 2014)

Pada tahun 2009 lalu, sebuah artikel hasil riset yang berjudul "Exploring the Impact of Lean Management on Innovation Capability" mengungkapkan bahwa penerapan lean manufacturing ternyata dapat mendorong kapasitas berinovasi (Chen dan Taylor, 2009). Temuan empiris tersebut kemudian dibuktikan lagi melalui beberapa hasil riset tentang implementasi lean manufacturing diantaranya dilakukan pada industri otomotif di Malaysia mengungkapkan bahwa pengaruhnya signifikan terhadap daya saing melalui variabel mediasi kamampuan inovasi (Muslimien, Yusof dan Abidin, 2011). Hasil riset tersebut juga diperkuat dalam 
sebuah tesis yang menyatakan bahwa implementasi lean manufacturing pada industri garmen telah mengurangi non-value addes process yang kemudian berkontribusi pada daya saingnya (Paneru,2011). Bahkan juga dipetegas dalam sebuah hasil riset pada industri kecil dan menengah di Ghana bahwa penerapan lean manufcaturing berkontribusi besar pada efisiensi biaya produksi dan daya saing (Ontow, 2011).

Hasil riset lain yang mendukung temuan-temuan tersebut juga mengungkapkan bahwa lean manufacturing pada usaha kecil di Australia meningkatkan produktifitas. Sebuah artikel hasil penelitian yang berjudul Analyzing the Benefits of Lean Techniques: A Manufacturing Process Industry Case Study, mengungkapkan bahwa aplikasi lean manufacturing mempunyai benefit efisiensi dan produktifitas (Bajpal et all.,2014). Penelitian yang berjudul A Model for Implementation of Lean manufacturing in Indian Small Scale Industries mendapatkan bahwa lean manufacturing berdampak pada daya saing produknya (Marasini, 2014). Riset lain makin menegaskan bahwa implementasi lean manufacturing best practices pada industri kecil menengahNordin, 2011). Singkatnya, lean manufacturing memiliki peran besar dalam mereduksi non value added procsess, yang akhirnya meningkatkan daya saing. Untuk itu, berdasarkan beberapa kajian teori dan penelitian-penelitian terdahulu tersebut, maka rumusan hipotesis pada penelitian ini adalah (a) lean manufacturing berpengaruh signifikan terhadap non value added proccess, (b) Non value added proccess berpengaruh signifikan terhadap daya saing, (c) lean manufacturing berpengaruh tidak langsung terhadap daya saing melalui non value added proccess dan (d) lean manufacturing berpengaruh langsung terhadap daya saing.

\section{METODE}

Pada penelitian dengan obyek pengrajin sandal dan sepatu Toyomerto, Singosari, Kabupaten Malang, Jawa Timur ini menggunakan pendekatan explanatory research dengan metode kuantitatif. Pengumpulan data yang digunakan adalah teknik survei, suatu kajian yang mengambil sampel tertentu dari satu populasi dengan menggunakan kuesioner sebagai alat pengumpul data pokok. Unit analisisnya adalah semua pengarajin sepatu dan sandal di Toyomerto, Kabupaten Malang. Dari sifat hubungannya dengan variabel lain, penelitian ini terdiri dari variabel eksogen dan variabel endogen. Pada penelitian ini, variabel lean manufacturing sebagai variabel eksogen dan sebagai variabel endogennya adalah daya saing.

Berdasarkan telaah pustaka dan pernyataan hipotesis penelitian yang telah dirumuskan, maka difinisi operasional variabel penelitian secara lengkap adalah : a) lean manufacturing adalah suatu pendekatan sistematis untuk mengidentifikasi dan mengeliminasi semua aktivitas tidak bernilai tambah melalui perbaikan terus-menerus untuk memungkinkan aliran produk berjalan lancar dalam mengejar kesempurnaan, b) daya saing adalah posisi organisasi unik terhadap pesaingnya yang dapat diperoleh sebagian besar dari sumberdaya dan modal.

Sedangkan jenis data yang digunakan pada penelitian ini adalah data primer, yang diperoleh secara langsung dari para responden penelitian (pengrajin). Data primer pada penelitian ini diperoleh dari jawaban yang didapat dari kuesioner yang diberikan kepada responden penelitian, dan hasil dari pengujian yang dilakukan. Pada penelitian ini terdapat 8 indikator yang menjadi data primer. Jenis data ini didapat langsung dari penyebaran kuesioner kepada pengrajin sepatu dan sandal di Toyomerto, Malang.

Populasi pada penelitian ini adalah semua pengarjin sepatu di Toyomerto. 
Mengingat jumlah responden yang relatif besar dan untuk mengantisipasi adanya data yang cacat, teknik pengumpulan data yang digunakan adalah simple random sampling yaitu sebuah satuan sampel yang dipilih acak dengan tujuan untuk mendapatkan sampel dengan karakteristik tertentu. Menurut Sugiyono (2009), responden yang representatif dalam teknik analisis SEM adalah 100-200 orang responden. Karenanya, jumlah responden penelitian ini ditentukan 105 responden yang berkinerja baik, sebagai syarat analisis SEM.

Pada penelitian ini data yang dikumpulkan menggunakan daftar pertanyaan atau kuesioner. Kuesioner merupakan cara pengumpulan data dengan memberikan daftar pertanyaan kepada responden untuk diisi. Pertanyaan-pertanyaan yang terdapat di dalam kuesioner dibuat dalam bentuk pertanyaan dengan menggunakan skala 1-5 dari sangat tidak setuju sampai sangat setuju. Tentu, instrumen penelitiannya yang sudah teruji kevalidan dan reliabilitasya. Teknik analisis data yang digunakan adalah Structual Equation Model (SEM) sebagaimana pendapat Ferdinand (2009), secara bertahap akan menggunakan dua macam teknik analisis yaitu (a) Factor Analysis pada SEM, digunakan untuk mengkonfirmasikan faktor-faktor yang paling dominan dalam satu kelompok variabel dan (b) Regression Weight pada SEM, digunakan untuk confirmatory meneliti seberapa besar hubungan antar variabel. Selanjutnya, pemodelan SEM lengkap diawali pengembangan model, pembuatan path diagram, memilih matriks input dan estimasi model, evaluasi kriteria goodness-of-fit dan interpretasi model.

\section{HASIL DAN PEMBAHASAN}

Berdasarkan hasil analisis data yang dilakukan dengan program AMOS 22, gambar path diagram yang dihasilkan adalah sebagai berikut.
Gambar 1. Path Diagram Lean Manufacturing dan Daya Saing.

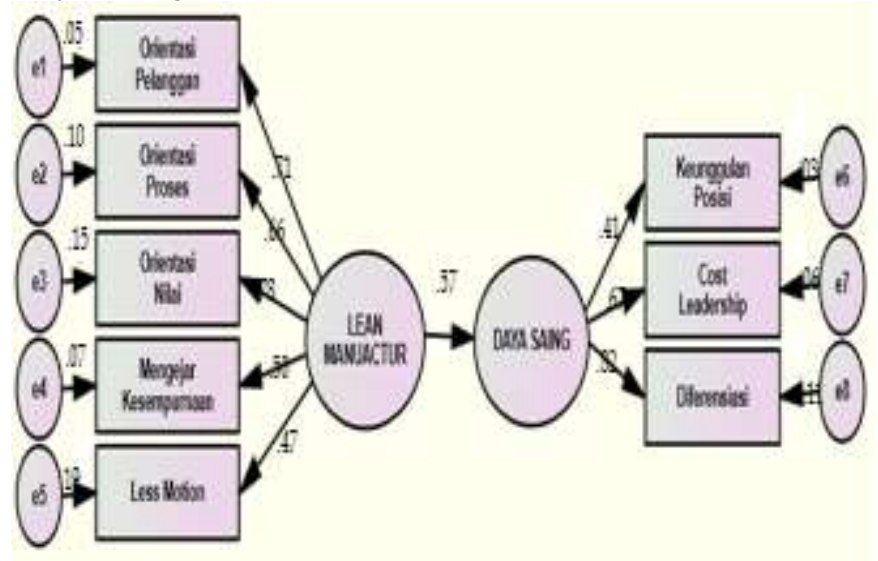

Sumber: Data Primer Diolah, 2016

Berdasarkan hasil pengujian terhadap model hubungan lean manufacturing dan daya saing, terungkap bahawa model ini fit dan dinyatakan baik. Hal itu dijelaskan pada tabel 1 , tentang indeks pengujian kelayakan model berikut ini.

Tabel 1. Indeks Pengujian Kelayakan SEM

\begin{tabular}{cccc}
\hline $\begin{array}{c}\text { Goodness of } \\
\text { Fit Index }\end{array}$ & $\begin{array}{c}\text { Cut-off } \\
\text { Value }\end{array}$ & $\begin{array}{c}\text { Hasil } \\
\text { Analisis }\end{array}$ & $\begin{array}{c}\text { Evaluasi } \\
\text { Model }\end{array}$ \\
\hline $\begin{array}{c}\mathrm{X}^{2} \text { - Chi- } \\
\text { square }\end{array}$ & $\begin{array}{c}\mathrm{P}=5 \%, \\
\text { Chi- } \\
\text { Square }\end{array}$ & 49.904 & Baik \\
& 68.6732 & & \\
\hline $\begin{array}{c}\text { Signifinacance } \\
\text { Probability }\end{array}$ & $\geq 0.05$ & 0.133 & Baik \\
\hline RMSEA & $\leq 0.08$ & 0.040 & Baik \\
\hline GFI & $\geq 0.90$ & 1.006 & Baik \\
\hline AGFI & $\geq 0.90$ & 0.890 & Marginal \\
\hline CMIN/DF & $\leq 2.00$ & 1.702 & Baik \\
\hline TLI & $\geq 0.95$ & 0.960 & Baik \\
CFI & $\geq 0.95$ & 0.949 & Marginal \\
\hline
\end{tabular}

Sumber: Data Primer Diolah, 2016

Menurut Ferdinand (2009), jika beberapa hasil evaluasi model dinyatakan baik, maka model yang terdapat pada gambar dapat dinyatakan fit. Selanjutnya, pada tabel 2 yang menjelaskan tentang regression weight 
juga terungkap bahwa pengaruh lean manufacturing berpengaruh terhadap daya saing karena memiliki nilai cr (critical ratio) lebih besar dari 2.00 dan juga mempunyai nilai probabilitas (p) masing-masing sebesar 0.00 .

Tabel 2. Regression Weights: (Group number 1 Default model)

\begin{tabular}{|c|c|c|c|c|c|c|}
\hline & & & $\begin{array}{l}\text { Esti } \\
\text { mate }\end{array}$ & $\begin{array}{l}\text { S. } \\
\text { E. }\end{array}$ & $\begin{array}{l}\text { C. } \\
\text { R. }\end{array}$ & $\mathrm{P}$ \\
\hline $\begin{array}{l}\text { Daya_ } \\
\text { Saing }\end{array}$ & $\begin{array}{l}<- \\
--\end{array}$ & $\begin{array}{l}\text { Lean_- } \\
\text { Manufac } \\
\text { turing }\end{array}$ & 0.57 & $\begin{array}{l}0 . \\
11\end{array}$ & $\begin{array}{l}5 . \\
17\end{array}$ & $\begin{array}{c}0 . \\
00\end{array}$ \\
\hline
\end{tabular}

Sumber: Data Primer Diolah, 2016

Maknanya bahwa lean manufacturing berpengaruh signifikan terhadap daya saing. Hal itu karena memiliki nilai critical ratio $5.17>2.00$ dan nilai $\mathrm{p}$ sebesar $0.00>0.05$. Temuan empiris ini tentu sejalan dengan beberapa hasil riset entang implementasi lean manufacturing diantaranya dilakukan pada industri otomotif di Malaysia mengungkapkan bahwa pengaruhnya signifikan terhadap daya saing melalui variabel mediasi kamampuan inovasi (Muslimien, Yusof dan Abidin, 2011). Hasil riset tersebut juga diperkuat dalam sebuah tesis yang menyatakan bahwa implementasi lean manufacturing pada industri garmen telah mengurangi non-value addes process yang kemudian berkontribusi pada daya saingnya (Paneru,2011). Bahkan juga dipetegas dalam sebuah hasil riset pada industri kecil dan menengah di Ghana bahwa penerapan lean manufcaturing berkontribusi besar pada efisiensi biaya produksi dan daya saing (Ontow, 2011).

Hasil riset lain yang mendukung temuan-temuan tersebut juga mengungkapkan bahwa lean manufacturing pada usaha kecil di Australia meningkatkan produktifitas. Sebuah artikel hasil penelitian yang berjudul Analyzing the Benefits of Lean Techniques: A Manufacturing Process Industry Case Study, mengungkapkan bahwa aplikasi lean manufacturing mempunyai benefit efisiensi dan produktifitas (Bajpal et all.,2014). Penelitian yang berjudul A Model for Implementation of Lean manufacturing in Indian Small Scale Industries mendapatkan bahwa lean manufacturing berdampak pada daya saing produknya (Marasini, 2014). Riset lain makin menegaskan bahwa implementasi lean manufacturing best practices pada industri kecil menengah (Nordin, 2011). Singkatnya, lean manufacturing memiliki peran besar dalam mereduksi non value added procsess, yang akhirnya meningkatkan daya saing. Untuk itu, berdasarkan beberapa kajian teori dan penelitian-penelitian terdahulu tersebut, maka rumusan hipotesis pada penelitian ini adalah a) lean manufacturing berpengaruh signifikan terhadap non value added proccess, b) non value added proccess berpengaruh signifikan terhadap daya saing, c) lean manufacturing berpengaruh tidak langsung terhadap daya saing melalui non value added process, d) lean manufacturing berpengaruh langsung terhadap daya saing.

\section{KESIMPULAN}

Berdasarkan hasil analisis penelitian dapat disimpulkan bahwa lean Manufacturing berkaitan erat dengan daya saing. Hal tersebut terungkap dari hasil uji statistik penelitian yang faktanya memang demikian. Maknanya, lean manufacturing berpengaruh nyata terhadap daya saing. Bahkan lean manufacturing bukan hanya berpengaruh langsung terhadap daya saing, melainkan juga mempunyai pengaruh tidak langsung pada peningkatan daya saing pengrajin Sepatu dan Sandal di Toyomerto, Kabupaten Malang. Untuk itu, temuan empiris ini dapat dijadikan sebagai pertimbangan bagi pemerintah daerah melalui Dinas Perindustrian setempat yang tentu sebagai leading sector pengembangan industri kecil ini. Dengan kata lain, dalam rangka meningkatkan kelangsungan para pengrajin tersebut diperlukan implementasi lean manufacturing pada kegiatan produksinya. Karena melalui implementasi 
model manajemen tersebut, produk para pengarjin tersebut akan lebih efisien sekaligus akan lebih berdaya saing di pasar dan terus maju.

\section{DAFTAR PUSTAKA}

Bajpal et all.,2014. Analyzing the Benefits of Lean Techniques: A Manufacturing Process Industry Case Study. International Journal of Mechanical Engineering and Information

Technology. 2 (5): 205-2012

Chen, H. danTtaylor, R. 2009. Exploring the Impact of Lean Management on Innovation Capability. Proceedings of lean manufacturing Seminar, August 2-6, Portland, Oregon.

Ferdinand, A.,2013. Metode Penelitian Manajemen: Pedoman Penelitian Skripsi, Tesis dan Desertasi. Edisi 4. Badan Penerbit Universitas Diponegoro, Semarang

George, M.L., Rowlands, David, Price, Mark and John Maxey. 2013.The Lean Six Sigma Pocket Tool Book. McGrawHill. New York.

Goriwondo W.M and Maunga N., 2012, Lean Six Sigma Application for Sustainable Production: A Case Study for Margarine Production in Zimbabwe, International Journal of Innovative Technology and Exploring Engineering (IJITEE) 1 (5): 2278- 3075.

Goriwondo G. dan Maunga R.,2012, Lean Six Sigma Application for Sustainable Production, Jurnal of African Business, 10 (22): 105-113.

Gupta et all. 2014. Role \& Importance of Lean Manufacturing in Manufacturing Industry. The International Journal of Engineering And Science (IJES). 3 (6) : 01-14

Landgehemm, H.V. 2011. People driven productivity: lean for small businesses. Management Series. Spring. p:13-18.
Marasini, B. et all. 2014. A Model for Implementation of Lean manufacturing in Indian Small Scale Industries, International Journal of Science, Engineering and Technology Research (IJSETR), 3 (5): 1538-1541

Muslimen, R., Yusof, S., Abidin, A. 2011. Lean Manufacturing Implementation in Malaysian Automotive Components Manufacturer. Proceeding of World Congress Engeeniring. Volume 1. London.

Nurazlin,P. dan Huihui,N. 2014. Managing Waste Elimination database in lean manufacturing: Improve Problem

Solving Capability, American Journal of Engineering and Applied Sciences. 7 (2): 271-281

Paneru, H. 2011. Implementation of Lean Manufacturing Tools in Garment Manufacturing Process Focusing Sewing Section of Men's Shirt, Thesis in Management Science, Oulu University of Applied Sciences.

Nordin, N.et all. 2011. Lean Manufacturing Best Practices in SMEs. Proceedings of the International Conference on Operations Management and Industrial Engineering p:1-6. Kuala Lumpur

Ntow, J.R. 2011. Implemtation of Lean manufacturing in Small Industries at Ghana, Thesis in Management Technology, Institute of Technology, Stockhlom

Putran et all. 2014. Value Stream Mapping : A Lean Tool. The International Journal of Business \& Management. 2 (4): 100-104

Tamrakar, S.. Tiwari, A., Tandon, T. 2014. Implementation of Lean Manufacturing Principles in Foundries. Management of Engineering International Journal, 4 (2): 46-50 